\title{
ANALYSING MICROMECHANISMS OF INITIATION AND PROPAGATION OF SHORT FATIGUE CRACKS FROM RIVET HOLES IN THE ALUMINUMS SHEETS
}

\author{
Dorota Kocańda, Volodymyr Hutsaylyuk \\ Military University of Technology \\ Warsaw, Poland
}

\begin{abstract}
Researched initiation and propagation of short surfaces fatigue cracks out of open in double-sided botch laminated sheet of aviation aluminum alloy 2024-T3 at stable amplitude one-sided bend $(R=0.1)$. Research of the initial stage of development of cracks is realized by use of a SEM microscope, and it allowed to set the place of origin of crack and mikromechanisms of fracture of aluminum sheets, and also type of front of crack. Established a large enough scatter of velocity of propagation in the area of development of short cracks, which for a sheet from this alloy, with a thickness of $3 \mathrm{~mm}$, reaches $0.5 \mathrm{~mm}$. On the basis of fractografy researches modified model of analytical description of propagation of short fatigue crack is proposed.
\end{abstract}

\section{INTRODUCTION}

In today's world there are a great amount of transportation vehicles and devices, industrial equipment and other elaborate engineering designs of the different setting in use. As a general line all of them are projected to work during a certain term. At the same time their problem is a fatigue and structure damage of material, elements constructions in the process of exploitation, which can result in considerable reduction of projected term of exploitation in case of unfavorable conditions of work. From other side at good external conditions the use of construction is possible, considerably longer, than it was foreseen by a project term.

Especially topically this problem rises in aviation, as possibility for exploitation of construction within a tolerance damage.

It is necessary to notice that the process of fatigue damage accumulation actually takes place in two stages (Fig.1):

- accumulation of microdamages and propagation of short cracks at the level of structural component of material;

- the initiator and propagation of crack is in a construction to the critical size at which exploitation of construction is stops. 


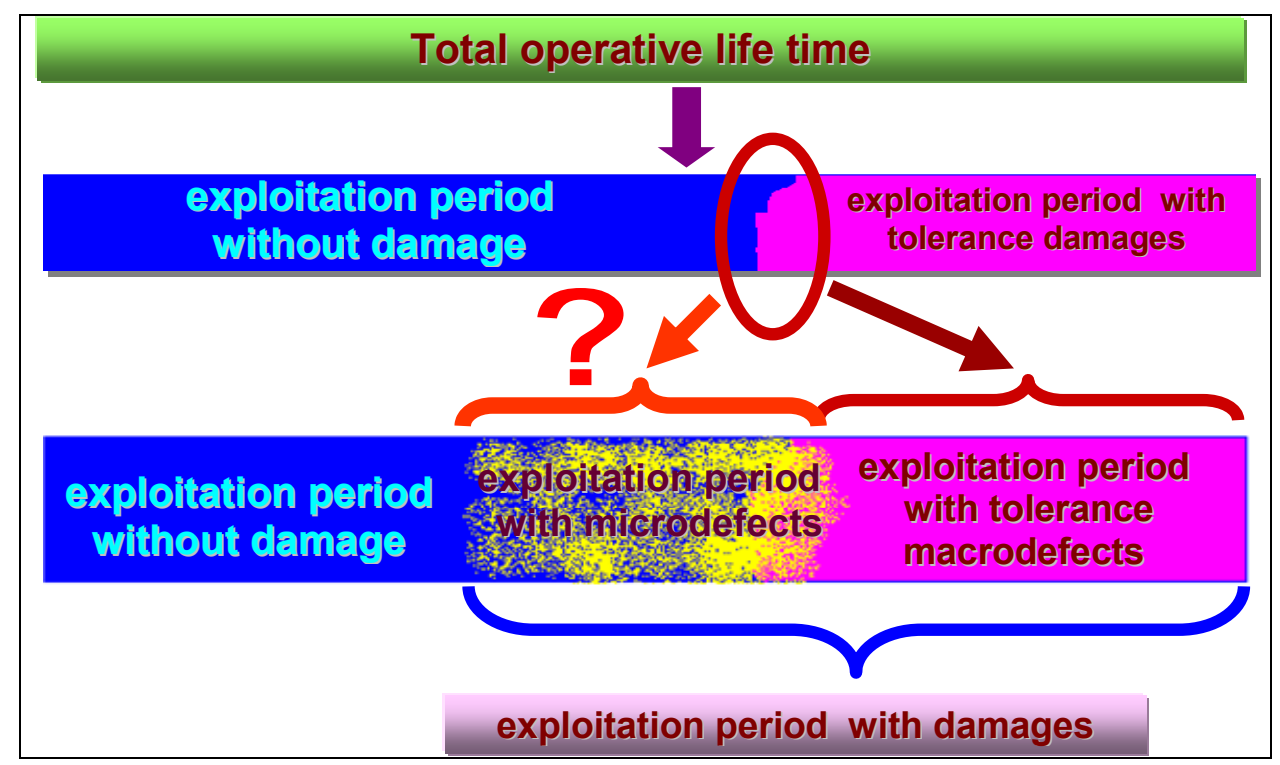

Fig.1 Scheme of accumulation fatigue damages during the total operative life time

At the time of prediction of remaining resource, in most cases stage II is considered, only where damage is visible and it is possible to control it.

However, for the operating resource considerable influence has the stage of primarily accumulation of fatigue damages, which will determine the size of remaining resource of construction, and period of exploitation with tolerance damage.

Determination of margin, for the stage is the stage of primarily accumulation of fatigue damages in relationship toward the planned resource of exploitation, to the stage of exploitation with the tolerance damage - actual scientific problem.

To describe the nature of propagation of fatigue cracks on macro level a theory is offered through Paris-Erdogan, and applied [1]. However, in the case of microcracks this theory is unavailable, since it does not to take into account a nature of propagation of short crack. This problem was taken into account more intensively and developed through Miller with his collaborators. [2]. In tests it was ascertained, that short crack begins to propagate more intensively by jumps with delays on barriers (border of phases, grains, include (Fig.2, 3) [13]. This phenomena can not be described with the use of the theory of Paris-Erdogan.

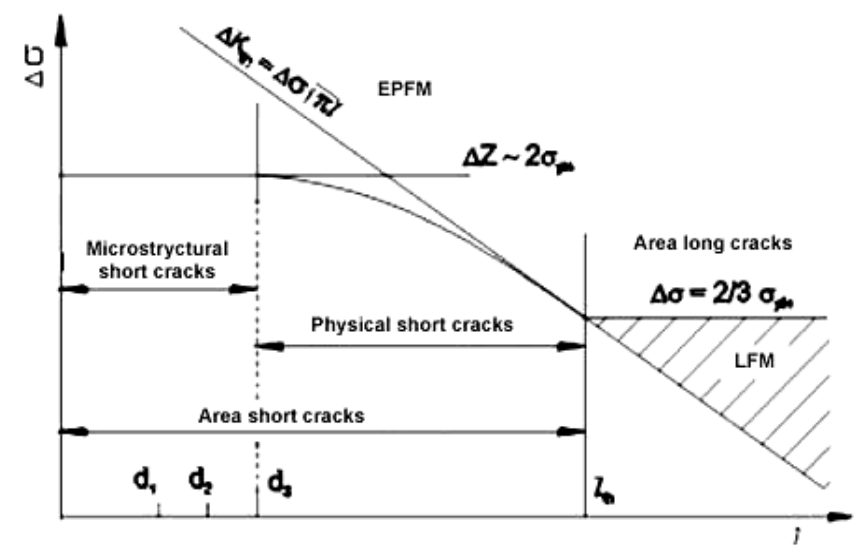

Fig.2 Conception area of shorts fatigue cracks

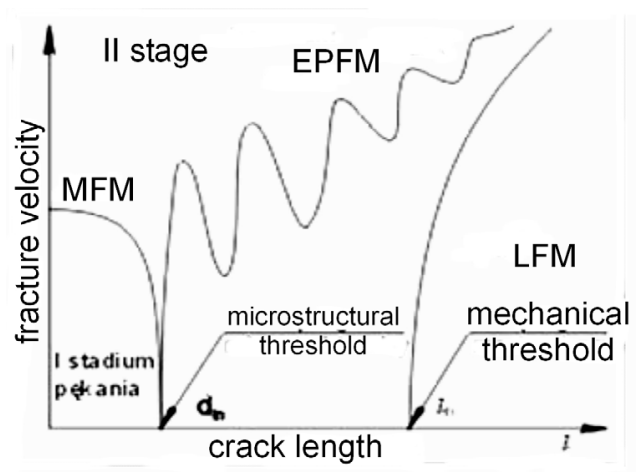

Fig.3 Scheme presentation of velocity propagation fatigue cracks in area of short and long cracks

To explore that it is necessary to carry out tests of processes of initiation and propagation crack on microlevel. Also, in that field there are not set one hypotheses, however it is possible to select some general principle. 
It is expected that a source of fatigue cracks appears in the thickness of sliding tracks on the surface of crystals. Sliding tracks create ledges and ditches as a result of changes in direction of sliding at the change of sign of loading. Under act of the oscillating loading the compression of separate planes can be also be done. Exactly this phenomenon is accepted for beginning of initiation for the short surface crack.

Basis of next mechanism for initiation of fatigue of defects is observed fact of creation of plural dislocation loops, the collaboration and forming of vacancy accumulation. The presence of this emptiness serves as the sources of fatigue crack. Under influence of loading, initial microcracks start from many sources. Failure initiation only one of those, which then becomes head macro crack.

The most complicated is the question of kinetics of propagation of short or small crack which are interpreted from different positions. At same time equation is offered for small crack propagation under different conditions, exploring the stages of initiation and development of small crack. However, simultaneously there is a necessity for a search of a general approach for the unique description of development of small and long cracks.

From the engineering point of view the problem of short cracks is very important. Since, by not taking into the account stages of propagation of short cracks leads to wrongful prediction of exploitation term and wrong estimation of reliability.

For this purpose one of directions in research is the initiation stage of propagation of fatigue cracks and creation of effective methods for prediction of durability of element with micro-defects and short sized cracks. According to above, the goal of this work is an attempt to create a method to estimate distribution of stresses at the front of the short crack which can be applied in engineering design.

S. Yarema offered to classify fatigue fracture materials with the conditional class into two stages: initiation and propagation cracks. [7]. Stage of initiation response the area of short crack. In this work on to that segment the parameters which used for description of behavior crack is a stress concentration factor Kt. The scheme of this classification is given on fig 1. Simultaneous in [6] it is given with to description of behavior of short crack can be applied approaches linear fracture mechanics especially for mechanical short crack.

On the basis of those authors from the next work [8] it is offered a model and method of design of characteristic of surface crack and angle crack at to the cyclic loading.

In offered models of analyzable propagation crack in the form of ellipse or it particles which keeps a form, however changes eccentricity and positions centers. For description of intensity of stress at the front crack, the averaging stress intensity factor is entered, in the plane perpendicular to loading, which describes discret changes of a crack resistance.

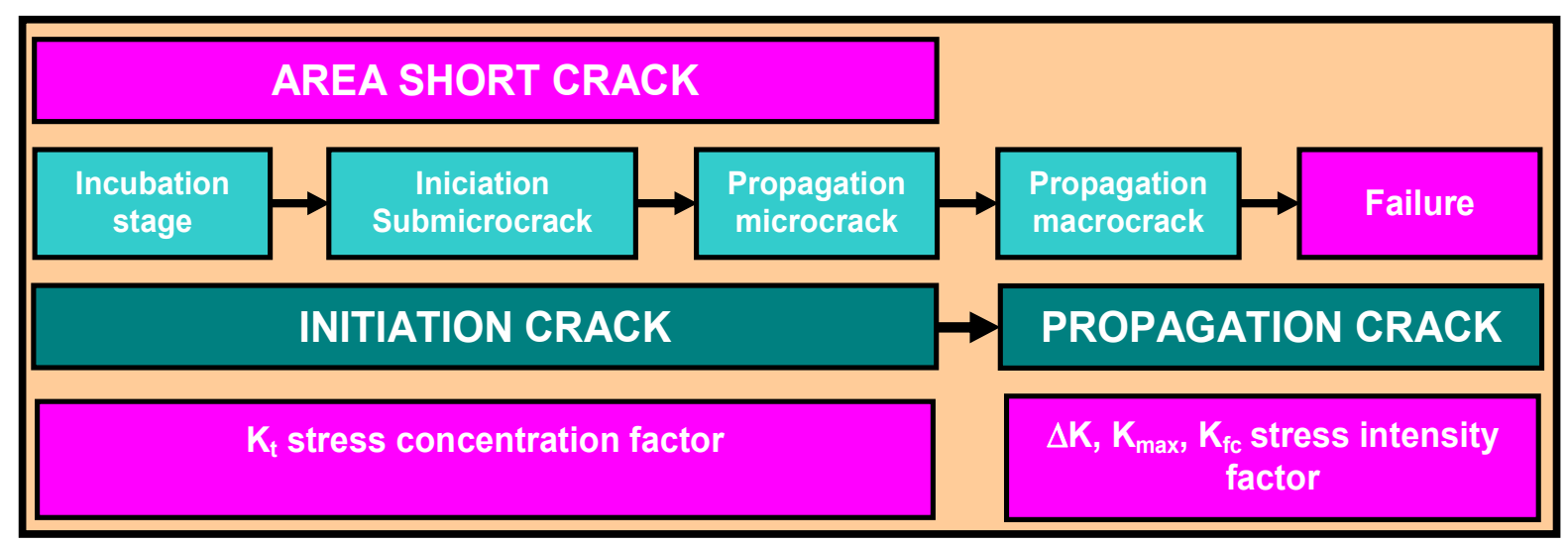

Fig.4. Stages fracture failure and definitions parameters 
In the works were considered three cases of such crack, which goes out on two outsides surfaces of specimen.

Exactly this modified case, based on basis of model offered for the design of distribution of stress at the front crack in the process of propagation, which also confirmed by the results from personal experimental researches.

\section{TESTING PROCEDURES}

Experimentally investigated specimens made from double-sided sheet, lamellar aluminum 2024-T3 with thickness of $3 \mathrm{~mm}$. Chemical structure of an alloy and the mechanical characteristics are given in table $1[1,10]$.

\section{Table 1}

\begin{tabular}{|l|c|c|c|c|c|}
\hline \multicolumn{7}{|c|}{ Chemical structure ( \%): } \\
\hline \multirow{4}{*}{$2024-T 3$} & $\mathrm{Cu}$ & $\mathrm{Mg}$ & $\mathrm{Mn}$ & $\mathrm{Fe}$ & $\mathrm{Zn}$ \\
\cline { 2 - 6 } & $3,82-4,04$ & $1,75-1,77$ & 0,56 & $0,08-0,18$ & 0,16 \\
\cline { 2 - 5 } & \multicolumn{2}{|c|}{ Mechanical properties in direct roller (LT) } \\
\cline { 2 - 5 } & $\mathrm{R}_{\mathrm{m}}, \mathrm{MPa}$ & \multicolumn{3}{c|}{$\mathrm{R} / 02, \mathrm{MPa}$} & \multicolumn{2}{c|}{$\mathrm{A}, \%$} \\
\cline { 2 - 5 } & $459-466$ & $339-345$ & \multicolumn{2}{c|}{$21,5-24,7$} \\
\hline
\end{tabular}

Aluminum specimens with length of $90 \mathrm{~mm}$ and width of $32 \mathrm{~mm}$ are cut out from a sheet in a direction forge rolling (LT) (fig 5.) Let's note, that specimens are cut out in two directions in a direction of forge rolling (LT) and perpendicular (TL) characterize by disorder of the mechanical characteristics in limits: $\mathrm{Rm}=447-466 \mathrm{MPa}, \mathrm{Re}=303-325 \mathrm{MPa}$. The thickness of a layer lamellar made about $0.12 \mathrm{~mm}$, and according to measurements radiography by a method the residual compressing stress in this layer makes about $40 \mathrm{MPa}$.

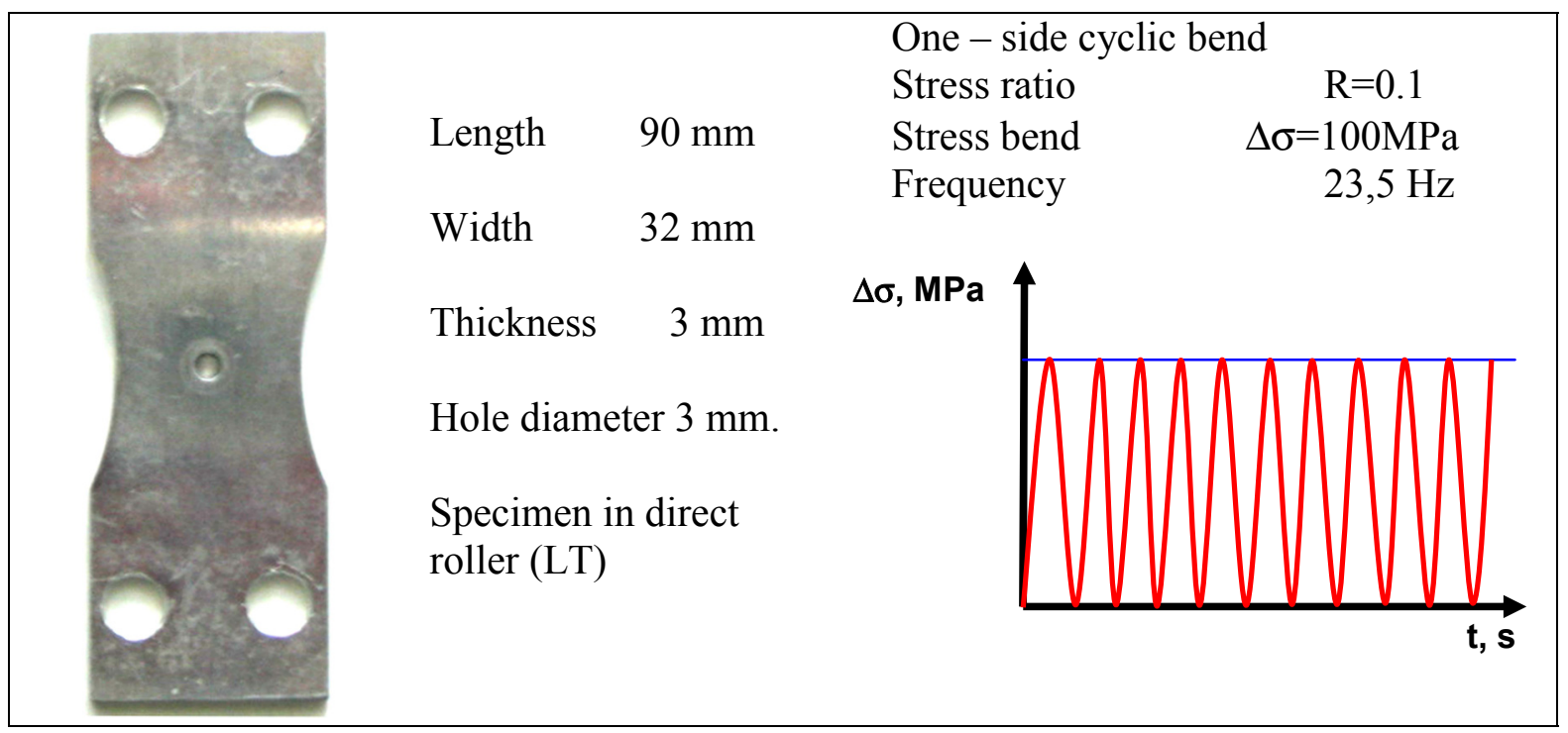

Fig.5. Test specimen and condition of loading

Specimens loaded in condition of one side cyclic bend with the coefficient of asymmetry of cycle of $\mathrm{R}=0.1$ on test machine, produced at Department Design Machines of Military University of Technology (Fig.6) 

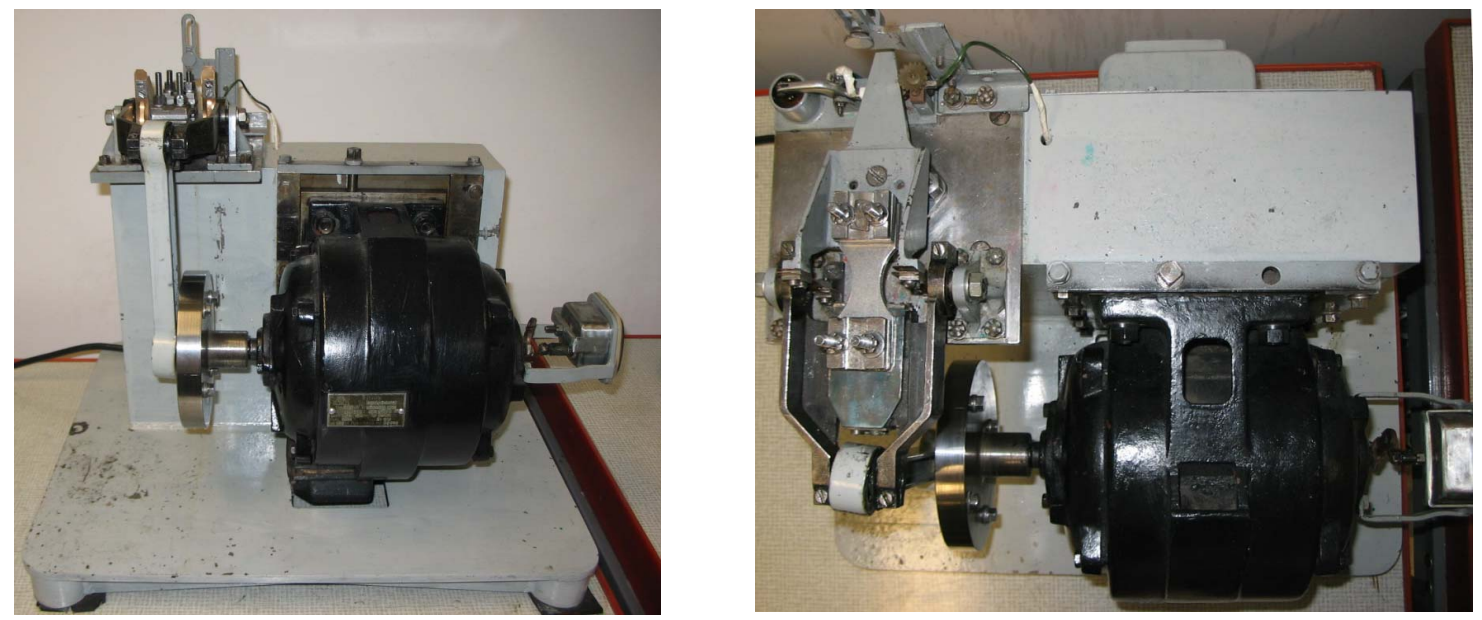

Fig.6. Test machine

The value of stress bending $\sigma_{\max }$ is accepted $\sigma=100 \mathrm{MPa}$, what correspond to mean bending stress in a skin sheet connections on a wing of airplane. The frequency of loading accepted at 23,5 Hz. Registration of cracks on surface specimens realized with a help of replicas, by the way of overlaying on the areas of propagation of cracks from both sides of hole. Pictures of these areas together with propagated cracks were analyzed in the optical microscope Neophot-2, and then next, were saved to the graphic program Lucia Measurement Version, which made possible to perform a precise measurement length of cracks on the display of the computer. The surface of specimen was not subjected to mechanical or chemical polishing to save the state of sheets, used as a skin of wings and also to expose influence of lamer (plating) on the initiation of cracks. Such actual state of surface caused some difficulties while observing initiation and propagation of short cracks. Certainly, we understand that registration propagation of short cracks by the replicas method is not precise. However, in these testes quantitative parameters were more pressing for which a method is detailed enough.

In the chamber of scanning microscope SEM all of specimens with a crack are analyzed on the different stages propagation their crack. Surface of specimens observed from the side of lamer (plating) and at same time from the inside of the hole. Beside for that the form of front crack is analyzed on the surface failure of specimen at the different number of cycles of loading and at different magnitude. Researched propagation of cracks fit with area of mechanical short fatigue cracks [6]. Application approach of linear fracture mechanics is correct for these cracks. Attention is concentrated on area of the short mechanical cracks, since those cracks are easily subjected to control and measurement by modern equipment. Consequently it is possible to take into account the area of the short mechanical cracks in the engineering methods of durability prediction of construction.

Surface short cracks on the different stages of their propagation on both sides of lamer (plating) aluminum sheet, that were viewed by a microscope SEM. Typical pictures that present surface short cracks are on an Fig. 7.

All of pictures are executed at the same magnitude. The most characteristic pictures are chosen for the tested specimens. Those pictures presents only stage of short cracks. On the pictures the deformation area of material is neatly visible in round the drilled hole in the form of dark band, which formed at drilling of the hole. Dark band has influence on initial propagation of short cracks. The sources of cracks are concentrated in the area of the hole rim margin and on a border between deformation area of material and virgin material of specimen (Fig. 7a). However, on this picture is very hard to make out local plastic deformation from an actual crack, especially in case of near hole rounding. For that cause additionally specimen observed under the optical microscope of Neophot-2 for the fixed actual status propagation cracks. It is marked, that in the initial stage of 
fatigue changes (after $10^{4}$ cycles), in the boundary of deformation area of material round hole, there were parallel dark areas on surface of the specimen by the rim of the hole, about almost identically mutual distance (Fig. 7a). The next cycles of loading caused forming of a net of local deformation in an area deformation of material around the hole. After $2,3 \cdot 10^{4}$.cycles is identified crack about long near $0.15 \mathrm{~mm}$ (Fig. 7b). Together with propagation of this crack, the new area of local plastic deformation is created before crack tip. Major initial deformation is not sufficient enough, that a crack could grow. At the same time was revealed fatigue damage mechanism of material during increase of surface crack. It was considered on an lamer (plating) surface of net of new local areas of plastic deformation, which preceded growth of crack (Fig. $7 \mathrm{~b}$ and c). Such jumping mechanism of increase of short crack on specimen surface conduced to period of falling velocity of fracture. At the same time this falling velocity of fracture on surface could be bound with propagation of crack in deep of sheet with already other velocity.

Behavior of a crack is similar inside hole, also leading to a turn about an angle of $45^{\circ}$ from formative surface hole. As much better as possible is it visible by the observevation of the surface specimen in the chamber of microscope SEM in edge area of the hole (Fig.8). Propagation crack on surface specimen promotes also forming together with the number of cycles of loading net of microcracks in cleavage oxidization layer lamer (plating) under influence of crack which nucleate from below layer of lamer (plating). Those microcracks connect and propagating in the plane of maximal tangent stress. It is the first stage of propagation of small cracks and related to fracture only along surface specimen. In the second stage propagation of crack is conducted in an identical degree along surface as well as in depth of sheet. Connections of a two microcracks on surface of specimen are presented in Fig.7d and 7e. Macroscopic track of crack, visible on surface of specimen, is perpendicular to planes of action of maximal normal stress (Fig. 7f).

For comparison on Fig. $7 \mathrm{~g}$ a propagation crack is presented from hole in specimen without lamer (plating). In those specimen cracks arose up later, than in lamer (plating) specimen and propagated quicker.

The charts of length of surface cracks at the function of number of cycles of changes of loading of $\mathrm{N}$ are presented on Fig. 9a, and Fig. 9b - in dependence on the relation of number of current cycles $\mathrm{N}_{\mathrm{i}}$ to the number of cycles, failure $\mathrm{N}_{\mathrm{f}}$ of specimen.

Each of the experimental points correspond to measured length of cracks in three specimens, did not lead to greater random spread. That is observed on charts on Fig. $4 \mathrm{a}$ and $4 \mathrm{~b}$ the discontinuity in motion of experimental points for specimen $6 \mathrm{kr}-\mathrm{LT} 100$ for $10^{5}$ cycles, or on $\mathrm{N}_{\mathrm{i}} / \mathrm{N}_{\mathrm{f}}$ $=0.25$ complete durability of specimen and in specimen $5 \mathrm{kr}-\mathrm{LT} 100$ on $2,8 \cdot 10^{5} \cdot$ cycles $\left(\mathrm{N}_{\mathrm{i}} / \mathrm{N}_{\mathrm{f}}=\right.$ 0.40 ). This discontinuity occurred for the removal of lamer (plating) from surface specimen by determination of numbers of cycles of loading and by subsequent propagation of cracks already with other velocity. In both specimens by removing lamer (plating) from surface specimen promptly falling a length of crack, almost to the zero. Especially it observed in specimen $5 \mathrm{kr}-$ LT100. After a removal lamer (plating) observed surface with optical microscope and there was no assertion of presence of cracks on the specimen surface. Also, replicas made in that area provided same confirmation. Therefore it means, that propagation of short cracks in lamer (plating) specimens in the first stage realize about by a generally only in the layer lamer (plating). The next cycles of loading promoted quick propagation of cracks on surface of a specimen that is without lamer (plating).

They were single cracks, which propagated from both sides of the hole in a perpendicular plane to the plane of action of bending stress and already become long cracks. On Fig. $4 \mathrm{~b}$ vertical lines which are broken are marking two areas (1) and (2) connected from length of short cracks and with correspondent the interval of durability, number of cycles of $\mathrm{N}_{\mathrm{i}} / \mathrm{N}_{\mathrm{f}}$ expressed through a relation. An area (1) belongs to the interval of propagation of short surface in alloy 2024-T3, which is set on basis of own tests for lamer (plating) sheets of this alloy about thick of $3 \mathrm{~mm}$. This section 
agrees with that data in publications [8-9]. An area (2) situated from the border of area (1) to the second vertical line, the area of short cracks in specimen without lamer (plating).
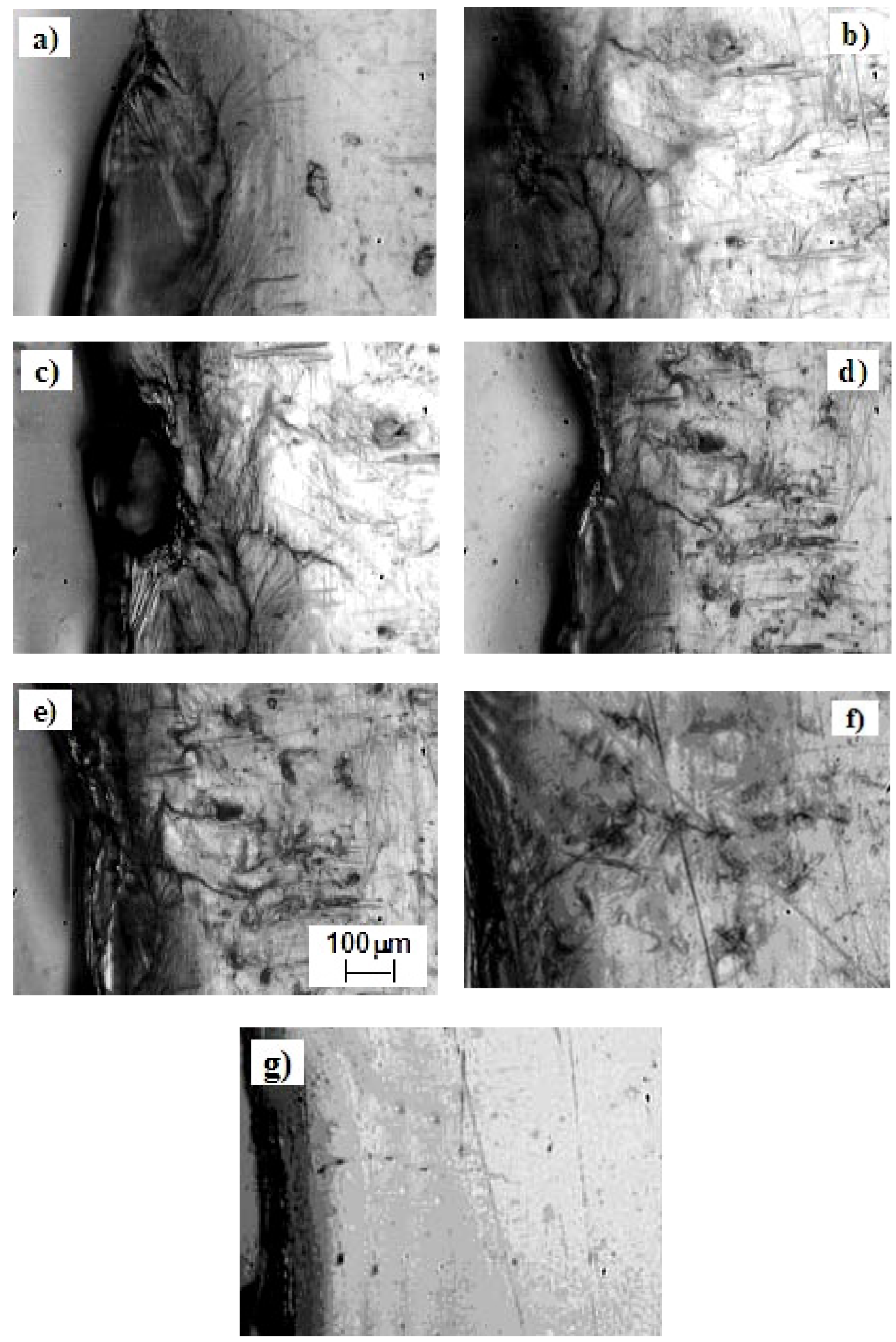

Cycle number:

a) $10^{4}$; b) $2,3 \cdot 10^{4}$; c) $2,9 \cdot 10^{4}$; d) $5,9 \cdot 10^{4}$; e) $9,5 \cdot 10^{4}$; f) $6,9 \cdot 10^{4}$;g) $2,8 \cdot 10^{4}$; (specimen of without of lamer)

Fig. 7. Surface short fatigue crack 
a)

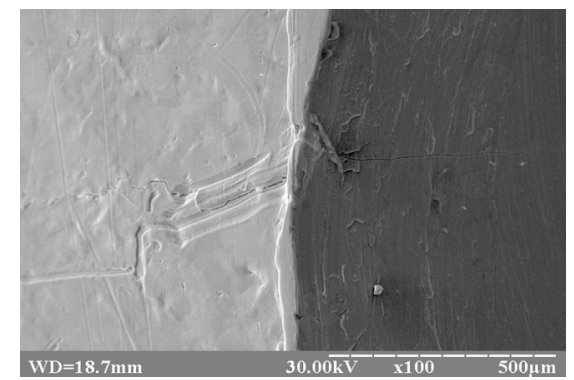

b)

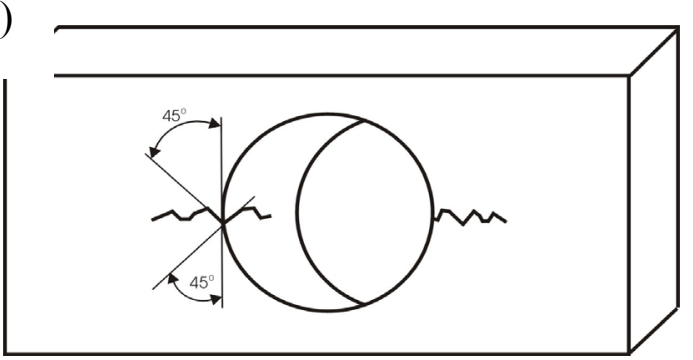

Fig. 8. Macroscopic track of crack growth on surface and also inside hole as per SEM(a) which is observed in a microscope and its scheme (b)
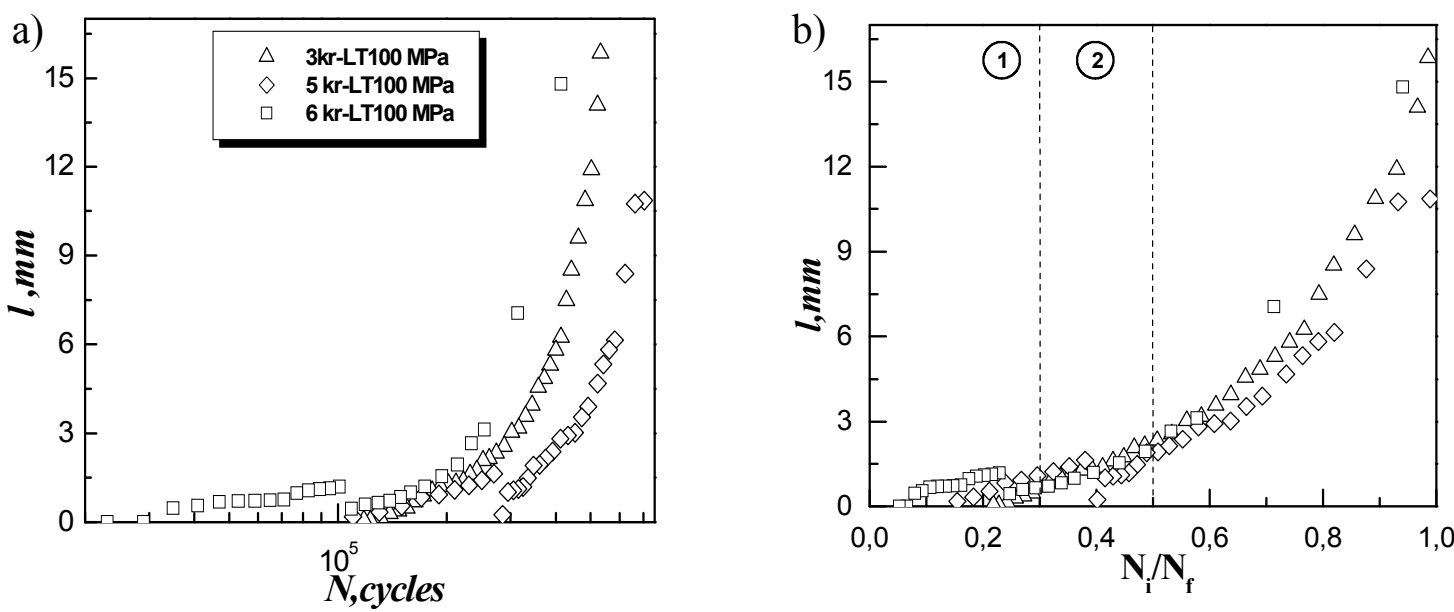

Fig.9. Charts of length of surfaces cracks in specimens from an alloy 2024-T3 in relation to the number of cycles of $N\left(\right.$ a) and from the relation of $N_{i} / N_{f}(b)$.

Like on Fig. 10, on basis of the same supposition two areas (1) and (2) are marked, and changes of velocity of growth of cracks in the section of short cracks in three tested specimens. The change of this velocity is attributed to the durability specimens of $\mathrm{N}_{\mathrm{i}} / \mathrm{N}_{\mathrm{f}}$ (Fig. 10a) and to the area of value of stress intensity factor $\Delta \mathrm{K}$ (Fig. 10b).
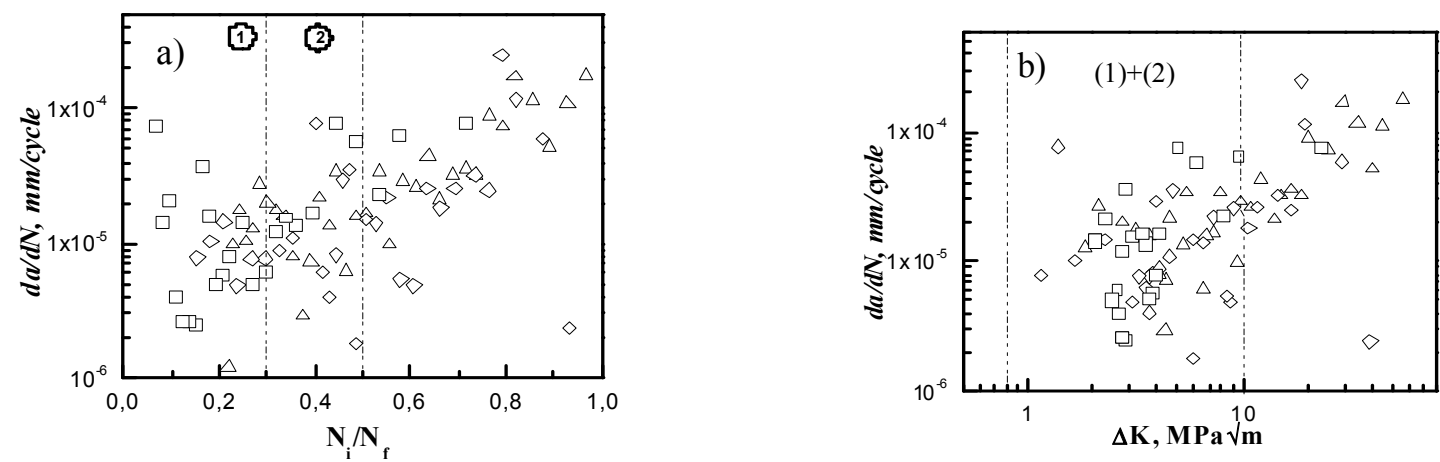

Fig.10. Velocity of cracks in specimens from an alloy 2024-T3 in dependence on the relation of number of cycles of $N_{i} / N_{f}(a)$ and from the area stress intensity factor $\Delta K(b)$. 
On an fig. 10b. area show (1)+(2) short cracks, registered in the specimens with lamer (plating) and without lamer (plating). Area that situated from the $\Delta \mathrm{K}(0.8-1)$ value $\Delta \mathrm{K}$ MPa $\sqrt{\mathrm{m}}$ the value $\Delta \mathrm{K}=10 \mathrm{MPa} \sqrt{\mathrm{m}}$. Out of this area the situated an area of long cracks growth. The design of coefficient $\Delta \mathrm{K}$ is carried out in compliance principle of fracture mechanics. Chart on Fig. 10 presents all of area of durability of tested specimens.

Through experimental points on the charts $11 \mathrm{a}$ and $11 \mathrm{~b}$, the lines of tendency are created by the method of the smallest squares, with a purpose distinctly pointing of tendency in the behavior of velocity surface cracks in a period included of $50 \%$ complete durability of specimens (Fig. 11a) and correspondence this durability area with changes of coefficient $\Delta \mathrm{K}$ (Fig. 11b).

a)

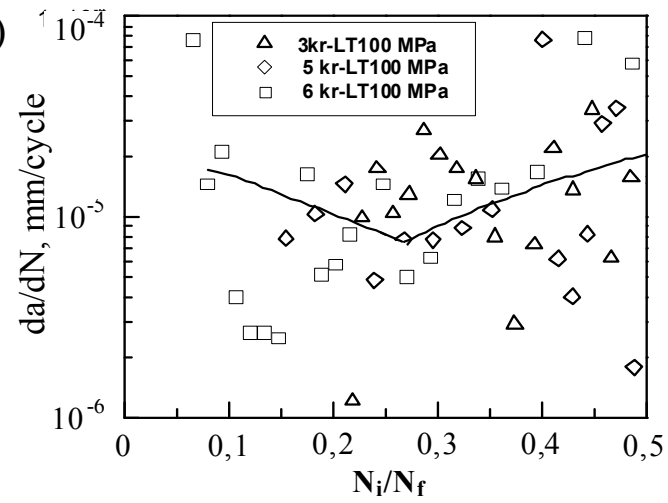

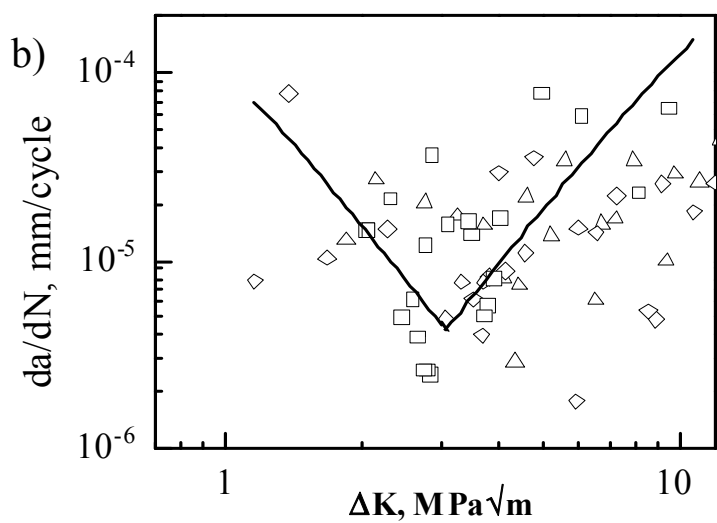

$\Delta K, M P a \sqrt{m}$

Fig. 11. Velocity of propagation of short surface cracks in dependence on (a) the relation of number of cycles of $N_{i} / N_{f}$ and also (b) area of stress intensity factor $\Delta K$

It is set from the own exploratory testings, that period of propagation of short cracks from hole in lamer (plating) from both side sheets makes near 25\% complete durability of specimens and velocity of cracks in specimens in this period changed from $10^{-6}$ to $10^{-4} \mathrm{~mm} /$ cycle. The value of coefficient $\Delta \mathrm{K}_{\mathrm{th}}$, from which that values of the short surface cracks can lead to properties of short mechanical cracks, is set on $\Delta \mathrm{K}_{\mathrm{th}}=3 \mathrm{MPa} \sqrt{\mathrm{m}}$. Higher than this value of coefficient $\Delta \mathrm{K}$ fracture in specimens realized in two directs - on surface and in depth of sheet. The given value can change, because depending on a kind and from the level of external stress applied to the element.

The present charts confirm large dispersion of experimental points of velocity of cracks and which already was mentioned repeatedly. It applies especially to area of short surface cracks. Dispersion of value velocity cracks is observed less on the border of transition to the long cracks.

Observations in the electronic scanning microscope SEM takes additional details, about the place of initiation and mechanism of growth of cracks from holes in lamer (plating) on both side aluminum sheets in condition of one-side cyclic bending $(\mathrm{R}=0.1)$. Those tests were realized in Ternopol Technical University in Ukraine. The goals of those tests was confirmation of more early results of analysis of pictures of areas of specimens, obtained by the method of replicas, as also to determine initiation source of crack, type of front, crack growth and also mechanism of fracture sheets.

In a microscope specimens observed with the different number cycles of loading, with registered different lengths of cracks. The specimens surface and inside of hole is analyzed at first. The typical pictures from these observations are given on Fig. 12. 

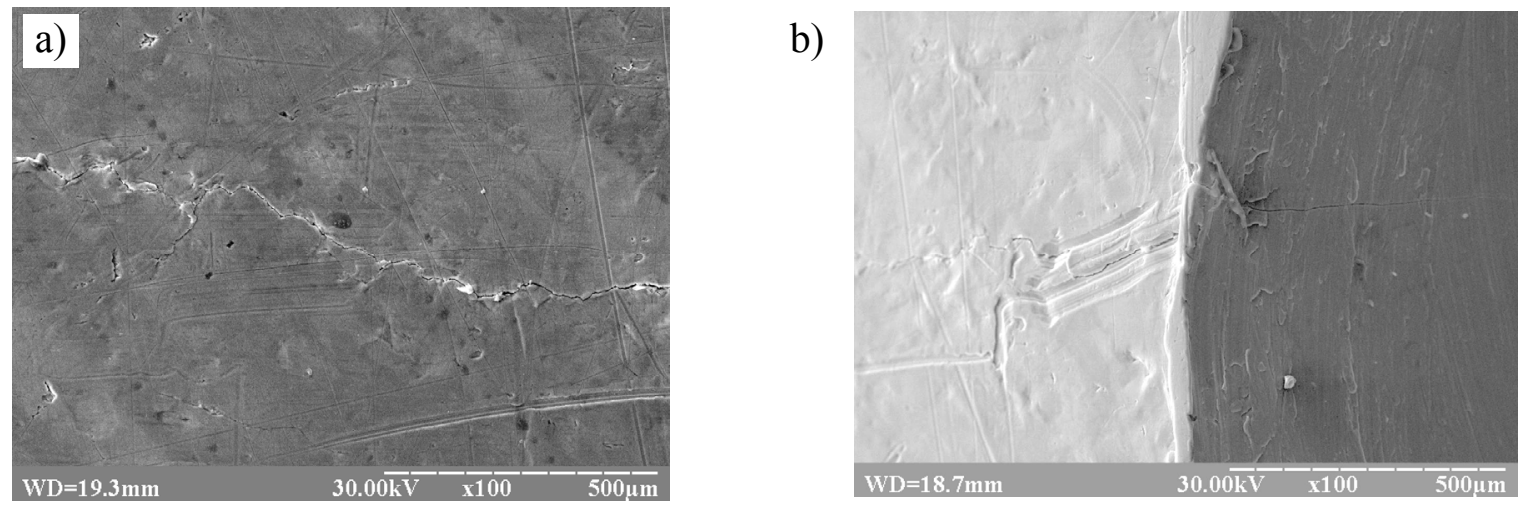

Fig. 12. Track of crack observed in SEM microscope on surface (a) and also on the inside of hole(b) (mag. 100x)

On a picture from left side visible 12a there is short surface crack which propagating in area of the hole edge. The track of this crack is a result of connection short cracks two-plane, mutually perpendicular, and consequently in the planes of action maximal tangent stress. In surrounding of this crack and also in a short remoteness from it the areas of local plastic deformation were marked in the figure of sliding bars. Lighter color of a track crack, distinguishes it from color areas of specimen, testifies to the presence of local areas of plastic deformation, which accompany propagation microcracks on surface lamer (plating). As fractography analysis of surface of failure of specimens shows (Fig. 13), cracks propagated under the layer of lamer (plating) on a border with base material and partly went out on the surface of lamer (plating) through connection of nearby areas of plastic deformation.

Tracks of mechanical scratch and damages visible on surface, Fig. 12 probably arose up in the transportation of sheets and during making of the hole. It necessary to mark, that on inside hole areas it is not marked a presence even local areas of plastically deformation. In the surrounding of the cracks was small practically unnoticeable area of deformation. These results of observation under microscope confirm more early suppositions about propagation character of crack in the moment of crack output on the surface of specimen.

In the process of testing under a microscope the initial and also finished length of small crack is set also for the tested material and method of loading of specimens. It is accepted, that minimum length of short crack on surface of specimen takes away $0.1 \mathrm{~mm}$, in same queue inside hole is about $0.06 \mathrm{~mm}$. On basis of more early testes, the maximal length of $3 \mathrm{~mm}$ is set also for short mechanical crack which propagate on surface of specimen. While for a crack which propagating inside hole in a specimen accepted length of $1.8 \mathrm{~mm}$ is on basis of measurement of general area of crack on the surface failure of a specimen. Area of a crack, related to the crack which propagation from hole along surface of specimen and takes a quarter elliptically form.

In the next task it was considered the fixed source initiation of crack in lamer (plating) aluminum sheet and also the mechanism of propagation of small crack. Much earlier testes of show that a crack initiates up under the layer lamer (plating) and grow in both the directions - in depth of sheet and in direction of its surface with different velocities. For that reason for the observation area is chosen on the border of layer lamer (plating) and base material and from the inside side of the hole (Fig.13). Picture on Fig.13a show this source initiation crack nearby hole rim on the border of lamer (plating) and base material. In this place there must be an area of large local plastical deformation as a cumulative effect, deformation from the process of making of sheet, roll lamer (plating) and at production of the hole. Cumulating of these deformations in the area of hole cases to exceeding local limits value of stress and deformation for material. Argument for that is brittle cleavage fracture in the preliminary deformation area material in round hole, formation of local facets about the largest in relation in comparing to the grain sizes of lamer 
(plating). The average grain size lamer (plating) takes away 80-90 $\mu \mathrm{m}$. Character of fracture facets is distinctly cleavage, to what testifies direction of inclination of beach of facets and also local cracks on their walls (Fig.13b). In comparing to fracture the layer lamer (plating), which also is cleavage (Fig.13a) a type of facets in lamer (plating) is a somewhat different because of areas of deformation of sheet and also direction of loading application. During the analysis of area source initiation crack, under other angle (Fig.13c) on surface of facets the strips fatigue, which formed as result of jumping propagation and grow of short microstructural of crack. Also, quasi-cleavage failure is indicated in this area. This character of failure comes forward also in the base material in surrounding of crack source, where very little failure strips come forward. However, facets are quite other size and visible small, almost round pits and also failure strips (Fig. 13c and 13f). Pits form in process failure on include of intermetallic phases in material, and create facets the carved relief of areas of crack with the distinct propagation direction of crack. This confirms a picture on Fig.13d. In area of crack source it is marked local crack (Fig.8d) which cross a few facets. It is distinctly visible on picture on Fig.13e, which demonstrate also quasi-cleavage character of failure in the area near source of crack.
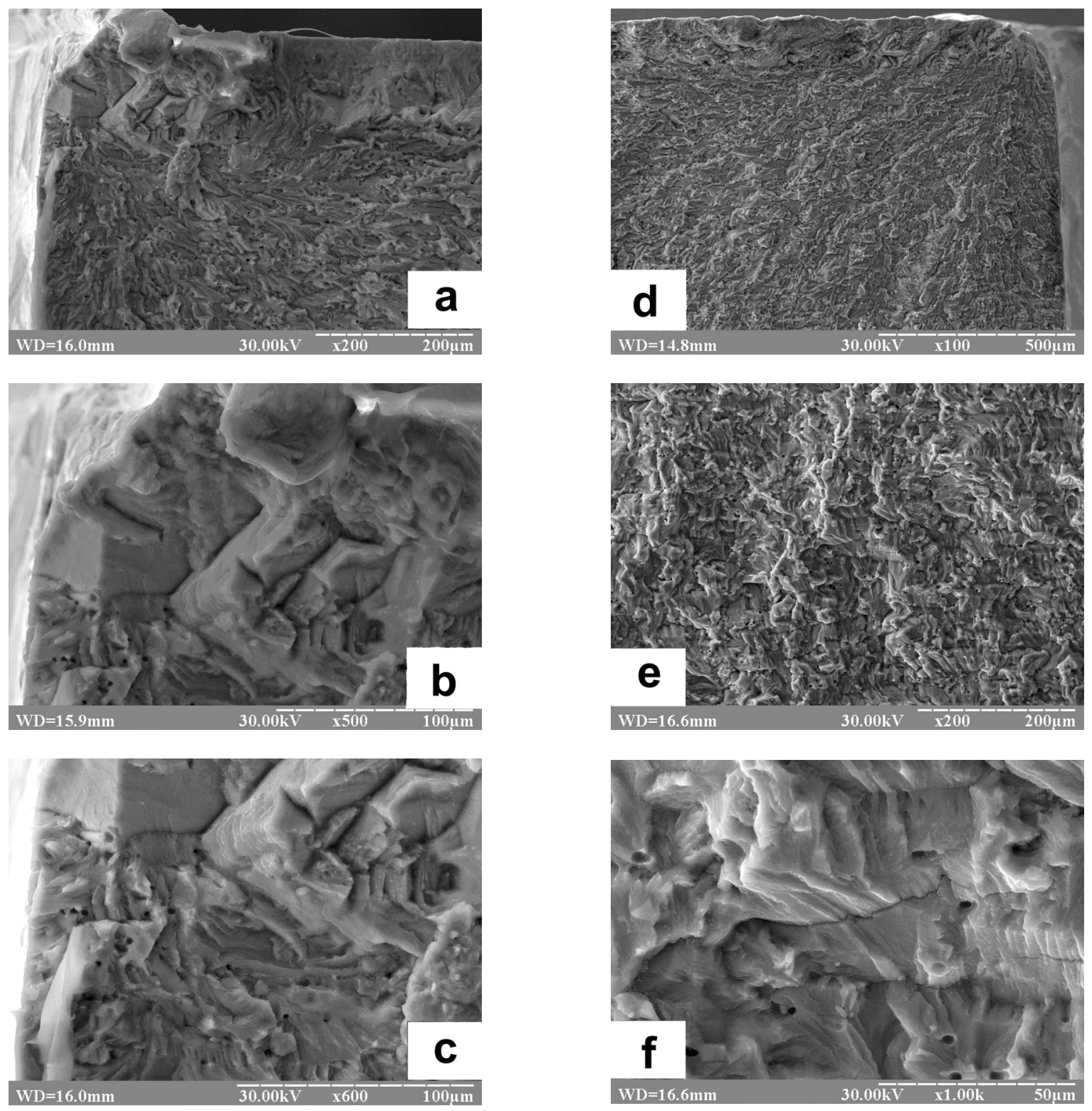

Fig. 13. Source crack on surface failure and also area of crack propagation near this source, which was observed under SEM microscope; explanations in a text 
As a next task which is realized in process of testing under microscope, there was determination of type of front crack and monitoring of sheet fracture. The typical pictures of small cracks on the different stages of their propagation in the specimens of LT presented picture on Fig. 14a and 14b. On a picture Fig. 14a crack on surface specimen is visible which propagates from the beach of hole (magnification 20x). A visible crack from the side of hole under other angle presented closer on a picture on Fig. 14b. On that picture, at magnification of 100 times, a crack which propagated observed inside of the hole. Picture of macro failure of specimens, that is observed at magnification of 25 times, together with the type of marked front of crack, presented on pictures, a Fig. 14c and 14d. In the initial stage of failure specimens at the front of a crack had form quarter elliptically with combs spines radial which went away from the source crack by the system visible on surface failure (Fig. 14c). At the end time the durability of specimen, the front crack transforms into of semi-elliptical type, what is demonstrated is a close picture of failure on Fig. 14d. Cracks front include the surface specimen and wall of a hole. It follows from the analysis of these two surfaces, that a crack in sheet propagation simultaneously in two perpendicular planes in depth of sheet along hole wall surface and along surface of a specimen. Pictures of failure of specimens from section, related to the increase of small fatigue cracks, illustrated on Fig. 14e and 14d. On a picture Fig. 14e is visible area initiation crack under the layer lamer (plating), in tensions plane specimen and wall of a hole. (left top corner of picture). The layer lamer (plating), somehow hides initiation of cracks, since it operate in its own pressing stress which is about the value of $40 \mathrm{MPa}$. As a results of that, in an initial period fracture specimens - crack quickly propagating in base material along hole areas, and in future followed go in direction of areas of sheet surface. Both these cracks had a semi-elliptically form (picture on Fig. 14g).

A crack which propagates in direction of sheet penetrated the layer lamer (plating), from below and became as an effect of a failure brittle passive layer lamer (plating) fracture.

As follows from the analysis of the last pictures the forming process of front crack is enough complicated and requires the additional explain. From this relation on a picture from left sides Fig. 15 , on picture of surface fracture of sheet, it is marked a contour type front of crack close to surface (contour a) and type of crack front inside the hole, along walls of a hole (contour b), which correspond as a initial stage of fracture sheet. These two fronts of cracks unite between itself, creating a general front about to quarter-elliptically form (contour c). Scheme of increase during and connections of two areas of cracks in one general front of crack are placed on the right side of Fig. 15. 

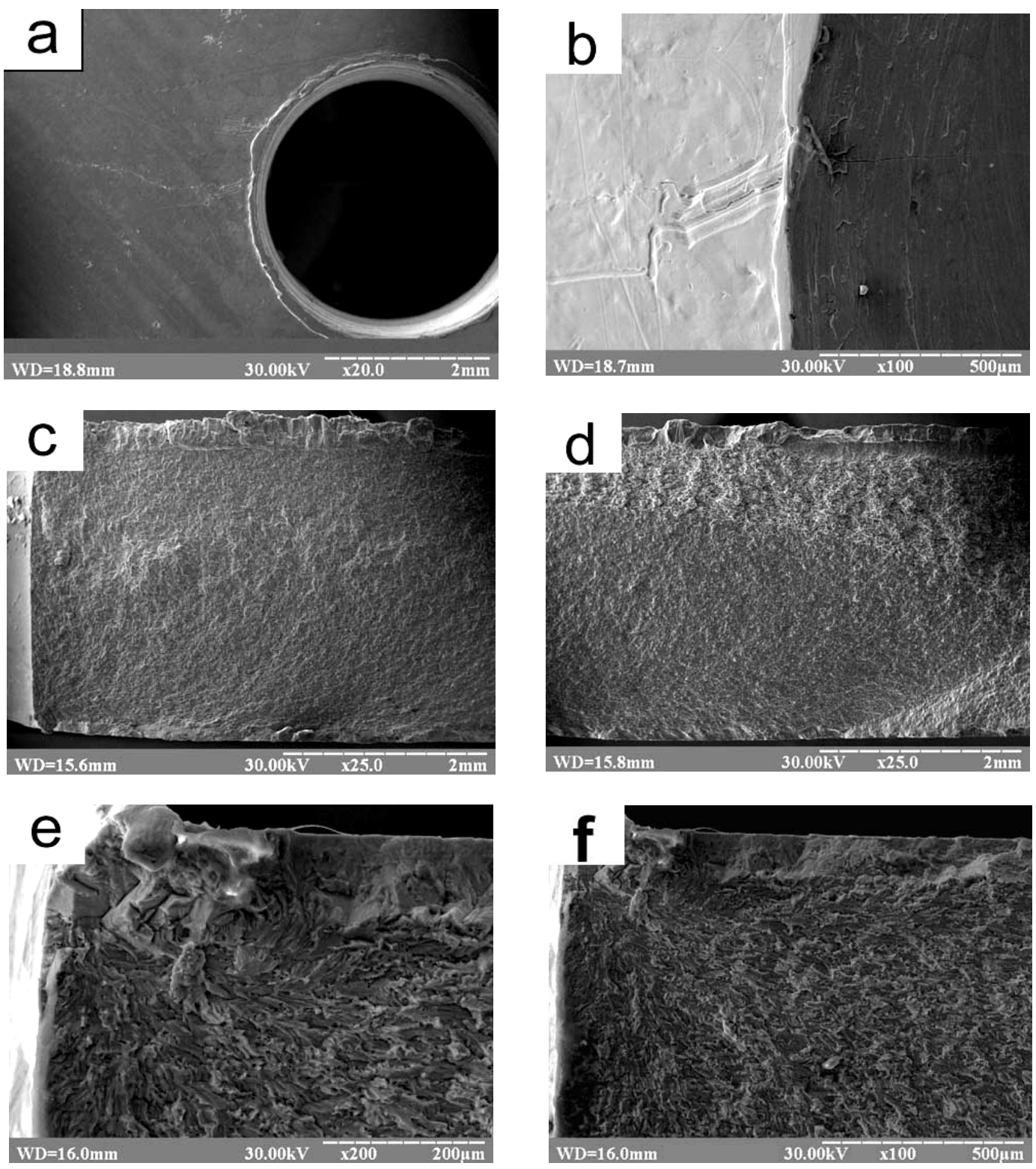

Fig. 14. Picture of fracture on surface and inside of aluminum sheet on different its stages; explanation in the text
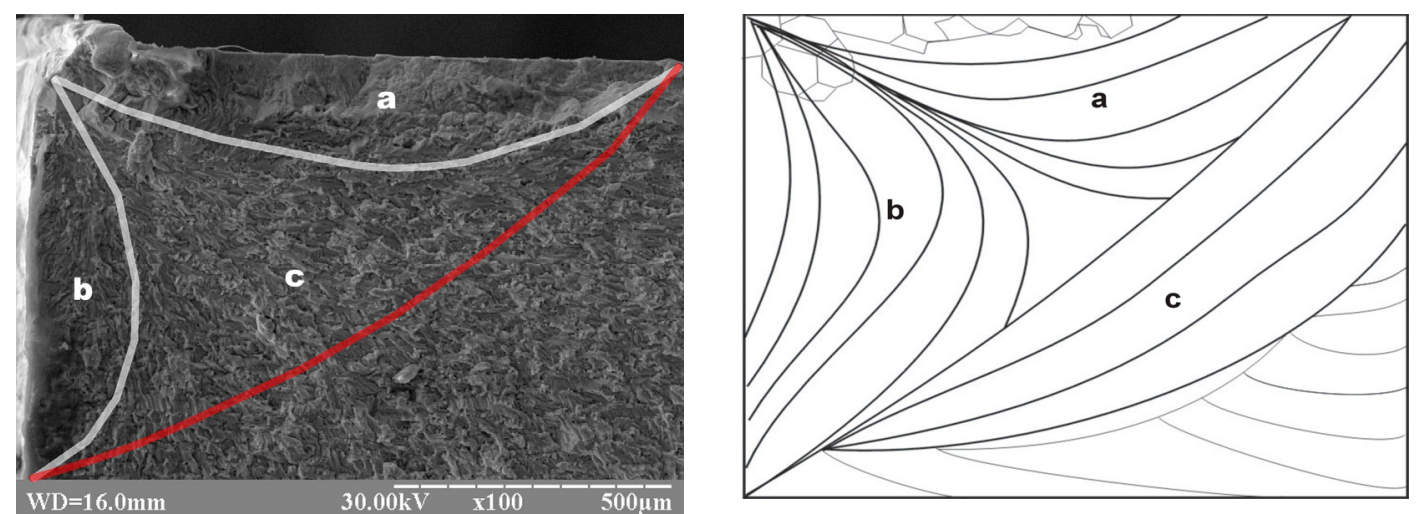

Fig 15 Picture of fracture on surface and inside of a aluminum sheet on different stages; explanation in the text 
For the analysis of micromechanics of propagation of crack at the level of grain research is conducted of macro fracture in two characteristic points: on the line front quarter-elliptically crack (Fig.16) and on the line of transition semi elliptic macrocrack in an area failure ( Fig.17).

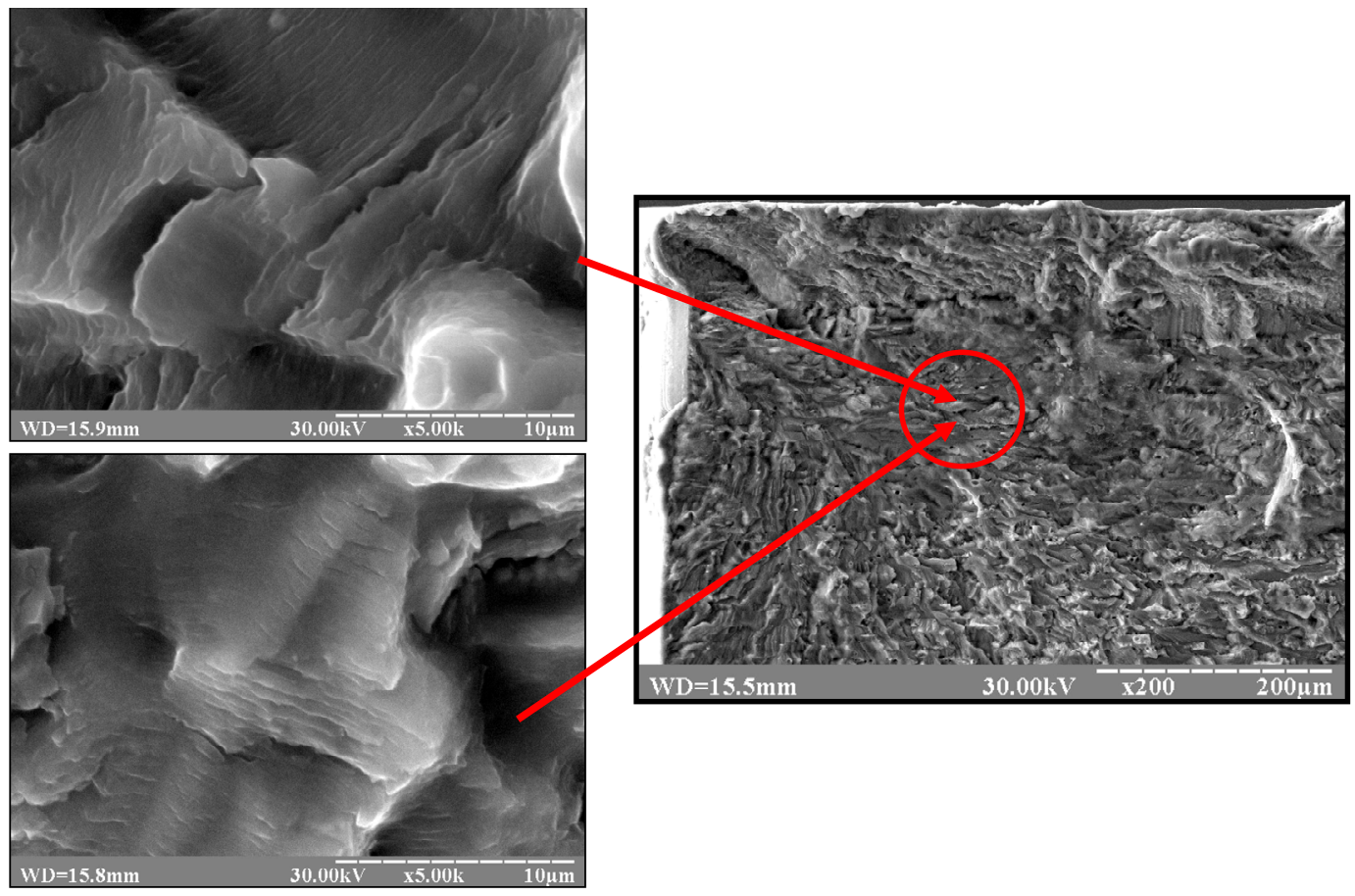

Fig.16. Fracture miromechanism on line front quarter-elliptically crack

As precise determination of line front crack is difficult enough considered that it is an area in which direction of combs on the surface fracture was directed in direction of width of specimens. An area was chosen on sufficient distance from the wall of hole and surface of lamer (plating) with the purpose of exception of influence of remaining residual technological stress on the micromechanisms of propagation of cracks.

The main picture of surface fracture in the tested area is characterized facets which form a brook pattern directed in direction of distribution of macrocrack. A pattern is formed as combs in direction of central part of specimen by facets with fluently rounding faces. On the surface facets there are fracture furrows in direction perpendicular to the axis of facets and propagation of macrocrack. In separate places the visible secondary cracks which as a rule are in the cavities.

Practically all cavities are formed around pit the form of that is very near to round. Most secondary cracks which are formed in the research area, pass through these pit which appeared in consequence of fall of the intermetal including.

Summary of these observations enables to draw conclusion that on this stage of propagation of fatigue macrocrack the mechanism mirofracture will be realized to a great extent by brittle fracture, but not without the exception of influence ductitility part.

Analyzing the behavior of crack in the second tested areas, will notice at once, that a change of direction of brook pattern is in direction of outside plane of specimen (Fig.17.) 

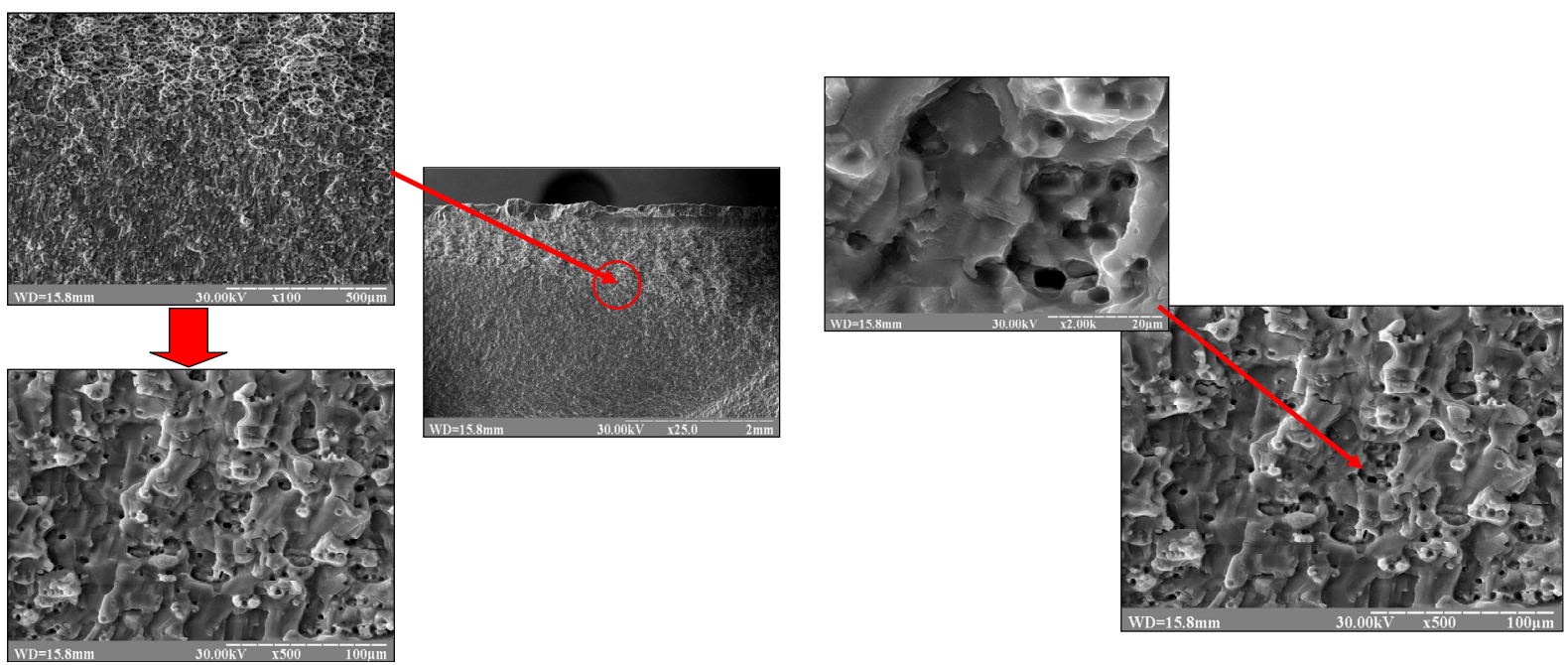

Fig.17. Fracture micromechanism on line of transition of semi elliptic macrocrack in an area failure

Even at a small magnification evident, that facets have considerably more flat slope, they are practically rounding. On the surface there are pits, some less size than those which are placed in cavities. The bottom of cavities is unequal, except for pit there are small combs with small pit on a top. The second microcracks go as on combs and on cavities, at what in cavities there are tracks a microcleavage on the plane of small combs.

In this case, probably, it can be said that, the mechanism of forming of macrocrack will be realized as break away with predominance ductility part as dominant, and with small part of brittle part on a microlevel.

Based on an analysis mechanism fracture in both areas of surface of failure, can draw conclusion, that failure of specimen takes place after the mixed mechanism in which the brittle is and ductility parts, which distribute differently on the initial and finished stage of propagation of macrocrack.

Additional influence on the micromechanism of fracture at the beginning of propagation of macrocrack and obtaining by it of critical size, realized remaining stress after mechanical operation at the production time of aluminum sheets.

For design use by a main a mathematical apparatus, offered in [8] based on other modified supposition.

For a design following suppositions are accepted:

1. Crack has a form of quarter-elliptic with the centers on the holes edge. Propagation of crack is done through the change of parameters of $\mathrm{a}_{\mathrm{x}}$ and $\mathrm{a}_{\mathrm{y}}$. (Fig.18a).

2. Boundaries of length of crack defined with $100 \mathrm{mkm}$ to $3 \mathrm{~mm}$ in the direction of axis $y$ and also $60 \mathrm{mkm}$ to $1.8 \mathrm{~mm}$ in the direction of axis $x$. (Fig18b)

3. Propagation of a crack is done discretely with the appointed step in to the each direction.

4. Calculations of effective stress intensity factor at the front crack, realized accordingly to a equations: $K_{\text {eff }}=\sqrt{ } K_{x}{ }^{2}+K_{y}{ }^{2}[6]$. 
a)

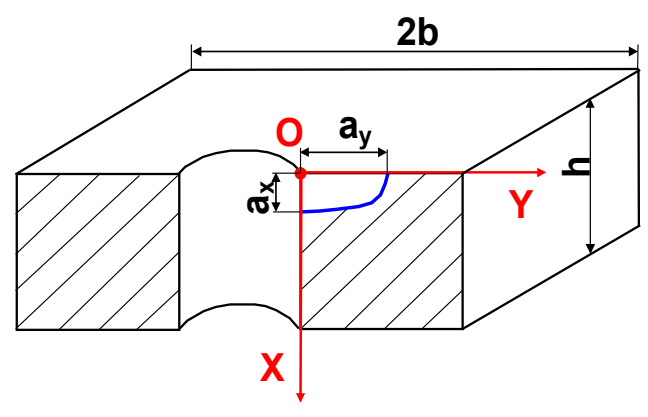

b)

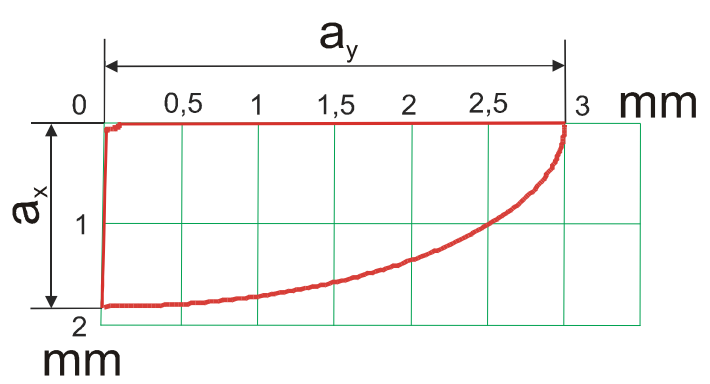

Fig 18. Scheme of a specimen with crack (a) and area of crack propagation (b).

Stress intensity factor $K_{x}, K_{y}$, which describes crack resistance in process of propagation, in discrete directions, calculated by equations [8]:

$$
\begin{aligned}
& K_{x}=\frac{\sigma \sqrt{\pi a_{x}}}{E} \cdot \sqrt{\frac{4+(E+D)}{3 \pi}} \cdot f\left(x_{s}\right) \cdot f\left(y_{s}\right) \\
& K_{y}=\frac{\sigma \sqrt{\pi a_{x}}}{E} \cdot \sqrt{\frac{4+(2 E+D)}{3 \pi}} \cdot f\left(x_{s}\right) \cdot f\left(y_{s}\right) \\
& \text { where } \\
& E(k)=\frac{\pi}{2} \cdot\left(1-\frac{k^{2}}{4}-\frac{3}{64} \cdot k^{4}\right) \\
& D(k)=\frac{\pi}{2} \cdot\left(\frac{1}{2}+\frac{k^{2}}{16}\right) \text {; } \\
& x_{s}=\frac{x}{a_{x} \cdot \sqrt{1-\left(\frac{y}{a_{y}}\right)^{2}}} ; \quad y_{s}=\frac{y}{a_{y} \cdot \sqrt{1-\left(\frac{x}{a_{x}}\right)^{2}}} ; \quad k^{2}=1-\left(\frac{a_{x}}{a_{y}}\right)^{2} \\
& f\left(x_{s}\right)=2 \sqrt{1+} x_{s}\left[\begin{array}{l}
1,3187+14,476 r^{6}+55,7388 r^{6}+ \\
-\left(0,7885+16,8024 r^{2}+105,2677 r^{6}\right) x_{s}+ \\
+\left(0,1769+2,3256 r^{2}+495289 r^{6}\right) x_{s}^{2}
\end{array}\right] \\
& r=\frac{a_{x} \sqrt{1-\left(\frac{y}{a_{y}}\right)^{2}}}{h} ; \quad f\left(y_{s}\right)=2 \sqrt{1+} y_{s}\left(1,3187-0,7885 y_{s}+0,1769 y_{s}^{2}\right) \\
& f\left(y_{s}\right)=2 \sqrt{1+y_{s}}\left(1,3187-0,7885 y_{s}+0,1769 y_{s}{ }^{2}\right)
\end{aligned}
$$




$$
K_{e f f}=\sqrt{K_{x}^{2}+K_{y}^{2}}
$$

All suppositions are based on the results of experimental researches which were partly described early. By using a models of quarter-elliptic crack localized on the edge of one hole in the case of symmetric loading, explain that in concrete area of propagation of the short crack initiation is not always done simultaneous on two sides of hole. This could have been bound with inaccuracy of making hole, asymmetrical loading or other parameters.

Generally, checked a stress distribution on the front of a crack; for this purpose it was not taken into the attention the crack propagation with correlation to amount of cycles of loading and other parameters of descriptions of material.

Calculations are conducted at $\Delta \sigma=100 \mathrm{MPa}$ in the conditions of the one-sided bending in a volume of small mechanical cracks at the early stage. The discreteness of the crack step is chosen so, that on every stage it remains looking like previous and keeps a similar form.

On Fig.19 the results of calculations are given in accordance to the geometrical parameters crack in both directions propagation, in 2-D and 3-D presentation.

As Fig. 19 shows, concentrations of stress on border of quarter-elliptic crack, higher compare with stress on a surface. This stage is more quickly propagation of crack into depth of specimen in the case angle crack.

It is noted that the beginning of crack, from the start of initiation propagation from the source under a sharp angle, however during propagation on a width it changes to a blunt angle, that consequently makes maximal length of crack not to show on a surface, but in section of a specimen.

Evidently, that this fact seriously influence on different type of calculation, since it is taken into an account that only longest crack which is not present on the surface of specimen and is characterizing the actual state of behavior of specimen or elements of construction.

a)

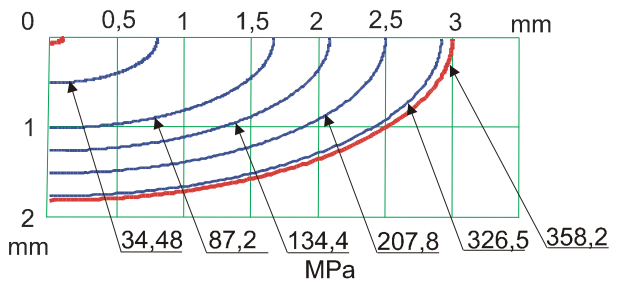

b)

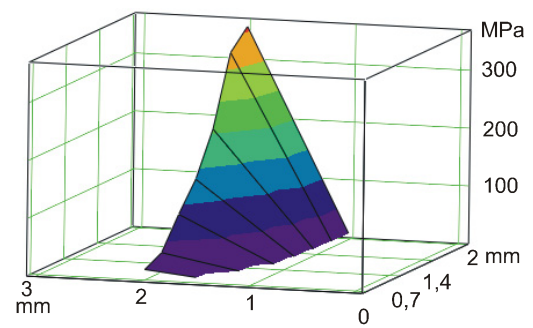

Fig.19 Distribution of stress on front crack and 2-D and 3-D scheme

\section{CONCLUSIONS}

1. On the basis of experimental tests, the fatigue stage of crack propagation was defined the stage of initiation or the area short crack propagation. It was exposed that in the process propagation crack in to aluminum alloy 2024-T3 crack form corresponds to the limited plane a line in a form quarter-elliptic with centers on edge holes on the borders of lamellar and virgin material.

2. Creation of crack form is done through propagation at the beginning of two semi-elliptic cracks along mutual perpendicular surfaces of specimen and wall of a holes. Propagation of a crack in depth of the specimen is done by one front, which is created as a result of association of 
perpendiculars cracks. Minimal sizes crack on surfaces of specimen and on the walls of holes were looked at after the process of testing, and about $100 \mathrm{mkm}$ and $60 \mathrm{mkm}$ were accepted

3. For description of crack propagation in the area of the short crack it is offered a modified model of propagation quarter-elliptic crack, which enables calculation of distribution of stress on the borders crack in a section of specimen. Received results well correlate with the actual obtained experimental results.

\section{REFERENCES}

[1] Paris, P., \& Erdogan, F. (1963). A critical analysis of crack propagation laws. Journal of Basic Engineering. 85(4), 60-68.

[2] Miller, K. J. (1993). Materials science perspective of metal fatigue resistance. Materials science and technology. 9, 453-462.

[3] Newman, J. C., Phillips, E. P., \& Swain, M. H. (1999). Fatigue life prediction methodology using small-crack theory, International Journal of Fatigue, 21(2), 109-119.

[4] Laz, P. J., \& Hillberry, B. M. (1998). Fatigue life prediction from inclusion initiated cracks. International Journal of Fatigue, 20(4), 263-271.

[5] Kocanda, D., Kocanda, S., \& Torzewski, J. (2003). Variable Amplitude Load Interaction in Fatigue Crack Growth for 2024-T3 Aluminium. Transactions of the Kielce University of Technology, 78, 269-278.

[6] Romaniv, O. N., Yarema, S. Ya., Nikiforchin, G. N., Makhutov, N. A., \& Stadnik, M. M. (1990). Fatigue and Cyclic Crack-Growth Resistance of Structural Materials. In: Panasyuk V. V. (Eds.), Fracture Mechanics and Strength of Materials. A Handbook [in Russian], 4, Kyiv: Naukova Dumka.

[7] Kocanda, D., Hutsaylyuk, V., \& Hlado, V. (2007). Analize propagation short fatigue crack from hole and micromechanism fracture lamer sheet aluminium alloy 2024-T3. Military University of Technology WAT Bulletin, 56(4), 37-54.

[10] Halliday, M. D., Cooper, C., Poole, P., \& Bowen, P. (2003). On predicting small fatigue crack growth and fatigue life from long crack data in 2024 aluminium alloy. International Journal of Fatigue, 25(8), 709-718.

[11] Kocanda, D., Kocanda, S., \& Kulec, P. (2005). Short fatigue crack in avia aluminum alloy 2024-T3. Scientific Papers. Mechanics [in Polish]. Technical University of Opole, 83(2), 8390.

[12] Li, X. D. (1996). Micromechanical model of stage I to stage II crack growth transition for aluminium alloys. Theoretical and Applied Fracture Mechanics, 24, 217-231. 